\title{
YANICK LAHENS, L'Oiseau Parker dans la nuit et autres nouvelles
}

\section{Roberto Ferraroni}

\section{OpenEdition}

\section{Journals}

\section{Edizione digitale}

URL: https://journals.openedition.org/studifrancesi/23349

DOI: 10.4000/studifrancesi.23349

ISSN: 2427-5856

\section{Editore}

Rosenberg \& Sellier

\section{Edizione cartacea}

Data di pubblicazione: 1 avril 2020

Paginazione: 231-232

ISSN: 0039-2944

\section{Notizia bibliografica digitale}

Roberto Ferraroni, «YANICK LAHENS, L'Oiseau Parker dans la nuit et autres nouvelles», Studi Francesi [Online], 190 (LXIV | I) | 2020, online dal 01 mai 2020, consultato il 03 août 2021. URL: http://

journals.openedition.org/studifrancesi/23349 ; DOI: https://doi.org/10.4000/studifrancesi.23349

Questo documento è stato generato automaticamente il 3 août 2021.

\section{(9) $\odot \Theta \Theta$}

Studi Francesi è distribuita con Licenza Creative Commons Attribuzione - Non commerciale - Non opere derivate 4.0 Internazionale. 


\title{
YANICK LAHENS, L'Oiseau Parker dans la nuit et autres nouvelles
}

\author{
Roberto Ferraroni
}

\section{NOTIZIA}

YANICK LAHENS, L'Oiseau Parker dans la nuit et autres nouvelles, Paris, Sabine Wespieser

Éditeur, 2019, $302 \mathrm{pp}$.

1 Il volume, sebbene di recente pubblicazione, non è in realtà un testo del tutto inedito. Si tratta, infatti, di una raccolta di novelle della scrittrice haitiana, apparse tra il $1994 \mathrm{e}$ il 2006. Le ventuno novelle qui contenute sono abbastanza equamente divise in tre parti: la prima, "Tante Résia et les dieux», ne conta sei; la seconda, «La petite corruption», sette; la terza, «La folie était venue avec la pluie», otto. Ognuna di esse contiene già il seme che germoglierà nell'opera più matura di Lahens e nei suoi romanzi pubblicati dopo il 2006 e vincitori di numerosi premi letterari. Attraverso la sua scrittura, l'autrice riesce a dipingere un quadro chiaro e nitido delle condizioni di vita sull'isola di Haiti. Ognuna delle novelle ha la particolarità di riuscire a sviscerare aspetti diversi della realtà isolana, così una volta il lettore si trova a muoversi tra $\mathrm{i}$ rumori forti di Port-au-Prince e poco dopo a vivere la calma e chiusa realtà di un villaggio di pescatori in riva al mare.

2 La maestria di Lahens sta proprio nella sua capacità di trasmettere al lettore, attraverso il giusto e ponderato uso delle parole, la realtà di cui sta parlando. Pagina dopo pagina sembra di vivere davvero Haiti, di conoscerla nel profondo, anche se non ci si è mai stati. Ne è un esempio evidente La Ville (pp. 107-138), in cui l'autrice descrive la città di Port-au-Prince nell'arco di ventiquattro ore attraverso gli spostamenti del protagonista: ciò che lascia stupefatti è la bravura di Lahens che, attraverso la scelta di parole ben calibrate, permette al lettore di "trasferirsi momentaneamente" nella città, di udirne realmente, leggendo, i rumori, le urla, le canzoni, il traffico: è una vera e propria esperienza uditiva vissuta attraverso la lettura. 
Così come i luoghi, anche i personaggi raccontati dall'autrice offrono uno spaccato concreto del mondo haitiano. Le principali protagoniste sono le donne, che non sono mai una uguale all'altra, ma spesso dotate di caratteri in netto contrasto tra loro: troviamo così la donna forte, la donna abusata e sfruttata, la donna disincantata, l'arrampicatrice sociale, la donna realizzata, con una vita felice e prospera, scappata dall'isola. Viene lasciato tuttavia spazio anche a molte figure maschili, perlopiù oppressi dal regime al potere, come per esempio Etienne, protagonista di Les Survivants (pp. 27-59).

4 Per completare il quadro dipinto da Lahens, un aspetto fondamentale è costituito dalle credenze popolari, dalla religione, dai riti di invocazione dei Loa, le divinità nella religione vudù molto praticata ad Haiti, che talvolta sono semplicemente accennati $\mathrm{e}$ fanno da sfondo alla narrazione, mentre in altre occasioni ne diventano i protagonisti. Proprio nella novella Tante Résia et les dieux (pp. 71-95) è presente una descrizione molto dettagliata di una cerimonia vudù in cui i partecipanti si abbandonano a danze e canti per invocare i Loa (pp. 91-94). Di notevole importanza sono anche i canti, non solo religiosi, che l'autrice introduce in diversi racconti e che permettono al lettore di entrare in diretto contatto anche con la lingua creola, tratto distintivo degli haitiani, così distante da qualsiasi altra lingua.

5 L'immagine della società che ci viene raccontata da Lahens attraverso queste novelle non è sicuramente confortante né attraversata dalla speranza di un cambiamento nel prossimo futuro. I personaggi che vivono ad Haiti sono tutti vittime di un sistema in cui sono la corruzione e i soprusi a spadroneggiare: non c'è giustizia, non c'è equità. Si ha l'impressione che l'unico modo per uscire da una condizione di sottomissione sia effettivamente lasciare concretamente l'isola, scappare, rifugiarsi negli Stati Uniti: solo lì è possibile, forse, trovare una vita felice e serena come quella di Marie Ange, protagonista di L'Homme du sommeil (pp. 291-302), novella che chiude la raccolta, che è scappata negli Stati Uniti, arrivando ad avere una vita felice, senza mai più mettere piede sul suolo della sua terra natale, pur portandola sempre nel cuore. Una vittoria quindi, ma che lascia un certo amaro in bocca.

6 Si tratta di una raccolta che aiuta il lettore a riflettere sinceramente e approfonditamente sulla situazione politica e sulla vita degli haitiani, facendogli prendere coscienza dei veri drammi che si consumano sull'isola. Lahens utilizza una forma lineare, un linguaggio chiaro, pulito, ma spesso tagliente, forte, per colpire in profondità la mente e il cuore di chi la sta leggendo. E riesce magistralmente nel suo intento. 